The primary goal of the RFP is to solicit proposals for clinical trials and mechanistic studies in kidney and islet transplantation. "The panel suggested starting trials on kidney patients because they are the least ill, compared with heart and liver transplant patients, and dialysis can be used as a backup for kidney failure," explains Turka.

Although the expert panel recommended that non-human primate studies in kidney and islet transplantation should be a priority of the RFP, animal studies were not included in the final proposal. "Instead, we are trying to set up a non-human primate network that will parallel the human trials," says Steve Rose, chief of Genetics and Transplantation Branch, NIAID and coauthor of the RFP. This work will be supported under a separate RFP, "Non-human primate transplant tolerance cooperative study group," which will provide $\$ 2$ million for one year of research into tolerance induction regimens in non-human primate models of kidney and islet transplantation.

Kristine NovaK, NeW York

\section{Genome sequencers square off down under}

The two rivals in the race to sequence the human genome each used the Human Genome Meeting '99 (HGM'99) in Brisbane, Australia (March 27-30), to demonstrate their confidence that they will be first past the post.

'Shotgun' sequencing pioneer Craig Venter, made a point of showing that he is unruffled by the announcement of an accelerated timetable for the publicly funded Human Genome Project. and boasted to delegates that his company, Celera, would soon bring online the world's second largest computer, and crank up 300 new sequencing machines capable of processing $140 \mathrm{mll}$ lion base pairs of DNA every 24 hours. Commenting on the National Human Genome Research Institute (NHGRI)-led international bid to map the genome, Venter told Nature Medicine: "I'm confident they're redundant."

Sharing the platform at HGM'99, leading NIH-funded researcher Richard Gibbs from Baylor Human Genome Sequencing Centre, Houstonwhose team will receive $\$ 13.4$ million from NHGRI as part of the $\$ 81.6$ million devoted to the accelerated schedule-conceded that Celera had "prodded" conservative academics to step up the pace, bringing the target for a rough draft of the human genome forward to April next year, with the blueprint complete by 2003 . However, Gibbs reiterated concerns about the ultimate quality and completeness of Celera's data, warning that attempts at wide patenting would be regarded as a mass intellectual property seizure-a "land-grab." Meanwhile, Venter assured delegates that although Celera could conceivably patent 100-300 genes of medical interest, it would not attempt to 'lock up' the human genome.

Venter disclosed that he is working on a genomics research paper to be submitted shortly to a "leading scientific journal," in tandem with an ethical review. The latter will encapsulate the conclusions of a mult-disciplinary group set up by US government adviser, Arthur Caplan, University of Pennsylvania, to wrestle with philosophical issues surrounding the prospect of synthesizing a new life-form. The integration of ethics with research, by publication of dual papers is "the model we should be striving for," says Caplan, adding that it would stop ethicists being simply reactive, and avoid the "frightened media" scenario that followed the Dolly announcement.

\section{In other genome research news..}

Both Celera and NHGRI might soon be outclassed by a new initiative unveiled last month that is being managed by The Wellcome Trust, which aims to develop a high-quality single nucleotide polymorphism (SNP) map and place it in the public domain with unrestricted access as it is constructed. The Trust, along with ten major pharmaceutical companies, is funding the two-year, $\$ 45$ million initiative, called The SNP Consortium, which also includes several academic research centers in the US and the UK. It will be led by independent chairman and CEO Arthur Holden.

Rada Rouse, Brisbane

\section{US lead in immunology research threatened}

Based on a subjective assessment by its members, the Committee on Science, Engineering and Public Policy (COSEPUP) panel on "International Benchmarking of US Immunology Research" has concluded that the US is the world leader in immunology research. Despite this, the panel voiced concern in a report released last month that the US may not be able to hold onto its pole position. Changes in Europe, such as increased availability of research funding and career possibilities and equivalent declines in these areas in the US, plus factors such as the rising cost of mouse facilities in the US, could jeopardize the country's dominance in this field.

Created to assess what will be the future position of the US, the panel calculated that the US puts out 60 percent of the world's annual immunology publications and was satisfied that it leads in each of the four subfields examined: cellular, molecular and clinical immunology and immunogenetics. It is likely to retain this lead, writes the panel, for the next decade. But the panel is worried that the US is only "among the world leaders" in other areas of immunology, such as research into transplantation and immunosupressive drugs, tumor immunology, lymphocyte development and inherited immunodeficiency.

There is further concern that US leadership does not stem from breakthrough discoveries evidenced by Nobel Prize awards, as half of the immunology Laureates are non-US citizens. Furthermore, based on "anecdotal evidence," the panel judged that there is a decrease in trained clinical immunologists to serve as principle investigators for large-scale clinical trials, brought about by lack of funding and training activities. There are, according to the report, substantially fewer US doctors specializing in immunology.

Moreover, the panel believes that European countries are able to support largescale clinical trials because of their "centralized government control of medical schools and research institutions;" and that improved opportunities will, in the future, keep foreign students at home and prevent them from traveling to the US where they have been contributing to the US' lead position in the field. A copy of the report is available at http://www.nap.edu/readingroom/index.html

KAREN BiRMINGHAM, LONDON 